\title{
The Feasibility and Acceptance of Social Media Interventions in Higher Education Classrooms of Developing Nations with Special Reference to India
}

\author{
Mangala Vadivu Vivakaran \& Neelamalar Maraimalai \\ Anna University, India
}

Submitted: 06.04.2018

Accepted: 12.06 .2018

Published: 16.07.2018

\begin{abstract}
Computers, during its entry into the academic domain, were forecasted to revolutionize the entire educational system across the globe. At present, similar expectations have been encircling the social media technologies. Many researchers claim that social media, when introduced in higher education environments, tend to enhance the students' learning experience by facilitating heightened levels of instructor-student interactions, peer learner support and learners' collaboration. Though social media is claimed to take the higher education learning to the next level, it is crucial to identify the readiness and proficiency of the instructors who play the main role in efficiently implementing these technologies in their classrooms. Especially, instructors belonging to the institutions present in developing nations are less likely to have proper access to some of the basic facilities (such as power supply or internet connectivity) required for social media integration. Hence, the present study aims at identifying the feasibility of introducing social media aids to the higher education classrooms present in Tamil Nadu - one among the eight Indian states having the highest number of colleges in the Nation.
\end{abstract}

Keywords: Social media; Higher Education; Technology acceptance; Educational interventions; Attitudes toward social media

\section{Introduction}

There has been an exponential increase in the popularity of online technologies with the advent of 'web 2.0'- also known as the social web - during the last decade. According to Kaplan and Haenlein (2010), the social web is an umbrella term that signifies a wide range of social media applications (such as the social networking sites, wikis, media sharing sites, forum, to mention a few) that mainly concentrates on the relationships between its users and facilitates the creation and exchange of User Generated Content (UGC). Communication, interaction, collaboration and sharing of digital contents are some of the central traits of these social technologies. The social web is also associated with terms such as 'dynamic', 'people-centric' and 'democratic' due to its unique traits and it is claimed to renovate the teaching and learning practices across the globe, making it learner-centric and more collaborative in nature (Brown, 2012). As a matter of fact, the use of social media technologies for educational purposes has been considered as one of the core changes that have been recorded in the academic sphere in the digital era (Means, 2010; Sanchez et al., 2014; De Wever, Hämäläinen, Voet, \& Gielen, 2015). This change eventually gave rise to educational social media platforms (such as ResearchGate, SlideShare, Google 
Scholar etc.) that provided dedicated service to the academic community fostering educational resources sharing and collaboration at a global level (Van Noorden, 2014).

The use of social media technologies for educational purposes have been predominantly associated with optimistic results (Barczyk \& Duncan, 2013; Gao, Luo and Zhang, 2012; Kitsantas et al, 2016; Parise, 2015) such as increased student satisfaction and participation, heightened collaboration among the learners and enhanced academic outputs, to mention a few. With a majority of the studies that have documented the educational applications of the social web mainly focus on higher educational institutions present in the developed nations, it is hard to predict its effect on institutions present in developing nations like India. Developing and underdeveloped countries tend to have a diverse digital profile and uneven distribution of digital resources - digital divide- affecting the overall access and digital connectivity of its people (West, 2015). The higher education classroom present in such countries can also be highly benefited by the educational potential of these social technologies. For instance, the country of India that currently houses the largest higher education system in the world is challenged by several issues (like unequal access and uneven distribution of quality education to all, rigid academic environment (Clement \& Murugavel, 2015), didactic lectures, inactiveness and passivity of the students (Jain et al, 2014), insignificant collaboration among the institutes etc.) that can be easily tacked with educational interventions from the social media fraternity but it currently impossible to judge the feasibility of introducing social media tools as educational aids in classrooms present in developing nations that are already battling against uneven access and allocation of digital resources. Hence, the present study targets to analyze the competency level of the Indian higher education system in supporting social media aids and the attitude of the faculty members in using a social media intervention in their classrooms.

\section{Social Media in Higher Education}

Social media technologies are progressively gaining momentum in the higher education sector due to its innovative and interactive nature that facilitates connections and communications to occur among the faculty and the students in the virtual spectrum (Lan et al, 2011). Existing studies such as Gupta (2014), Tess (2013), Manca and Ranieri (2015) and Karvounidis, Chimos, Bersimis and Douligeris (2014), to cite a few dealing with the use of social media applications as learning or mobile learning tools, have largely documented positive outcomes. For instance, Miyazoe and Anderson (2010) have reported that social media, when applied in an educational context, has the ability to promote collaborations by providing a mutual learning environment (such as wikis) that can be used by the learners as well as the teachers without any geographical constraints. In addition, these technologies provide important other features such as feedback, interactions and networking that are crucial for academic collaborations.

While social networking platforms like Facebook and Twitter are being used by the faculty members for sharing information and learning resources with their students (Veletsianos \& Navarrete, 2012); discussion forums, instant messaging applications and wikis assisted in online collaboration activities involving fellow learners (Hrastinski \& Aghaee, 2012). YouTube is popularly used for sharing and referring educational videos (Moran et al, 2011) and its educational potential is being widely experimented in the field of medical sciences (Barry et al 2016; Muniyandy et al, 2015; Tackett et al, 2018). Blogs, on the other hand, are envisioned to hold high pedagogical characteristics that are ideal for the higher education environment. Both textual and audio/video blogs are being vigorously examined in this context, especially in the field of language learning (Lee, 2017; Pavo \& Rodrigo, 2015; Sun, 2012; Tang \& Lam, 2014; Zheng 
et al, 2018) for vocabulary and oral training. Wikis were noted to enhance critical thinking skills of the learners (Wang et al., 2014). Social virtual environments such as Second Life is also gaining popularity in higher education settings. Collaborations in such simulated and immersive environment are reported to facilitate an in-depth understanding of the subject, real-world application of knowledge and development of a sense of virtual learning community among the learners as it inherently provides realistic visualization of peer learner support system - in forms of avatars/online characters (Ganem-Gutierrez, 2014; Hew \& Cheung, 2013).

Apart from these commercial outlets, dedicated social media platforms that exclusively cater to the requirements of the academic community began to emerge in the recent years. Educational social media platforms (such as Academia.edu, Edmodo, SlideShare, to mention a few) function with the aim of fostering seamless communication and information exchange between the primary stakeholders of the educational realm sites -students, faculty members and researchers. For instance, when Edmodo - an online social learning platform - was introduced as an intervention to English language learners belonging to the Arab Open University, it was reported to initiate active learning and also significantly enhance the writing style of the students (AlNaibi et al, 2018). Thus, learning through these social technologies has been increasingly recognized and supported by the academia and new instructional strategies are getting developed to harness the power of social media in order to supplement the formal learning environment (Ryan \& Tilbury, 2013).

Amidst all these positive claims and indications of social media technologies advancing the overall landscape of higher education, it is crucial to note that studies reporting the outcomes of the real-world implementation of such social media tools in colleges of the developing and underdeveloped nations are seldom to be found. A majority of the existing studies (Gros \& López, 2016; Kassens-Noor, 2012; Orús et al, 2016; Ward et al, 2015) report the findings of research conducted in developed nations. The lack of feasibility or the lack of facilities required for social media intervention to properly function in the higher education classrooms of developing or underdeveloped countries may be pointed as a reason for this research gap. In reality, higher education institutions present in these digitally disadvantaged regions have a high probability of not having proper access to basic facilities such as power supply or internet connectivity required for a successful social media integration. Hence, the present study aims to analyze the likelihood and feasibility of higher education institutions present in India in accepting and using technologically advanced social media applications as educational interventions.

\section{Research Questions}

In order to understand the readiness of higher education institutions present in India in accepting technologically advanced social media interventions and to identify the perception of the faculty members regarding such educational aids, the current study intends to answer the following research questions:

- What is the attitude of the faculty members towards the use of social media tools as educational aids?

- Do higher education institutions have the minimum facilities that are required to support social media aids in their classrooms?

- Does the environmental setting (urban/rural) of a particular institution influence the availability of facilities that are needed for social media integration? 
- Do factors such as 'availability of technological resources' and 'ease of use' influence the faculty members' attitude and intention in adopting advance technological aids for educational purposes?

\section{Methodology}

\section{Sampling and Data Collection}

The study employed an empirical research design where a large-scale survey was conducted among the faculty members of higher education institutions in Tamil Nadu. Tamil Nadu, one of the eight states in India possessing the highest number of colleges (Government of India, 2016), was chosen as the research area for the current study. The appropriate sample size for acquiring representative sample units from a total of 1,96,081 faculty members belonging to 2,364 colleges in Tamil Nadu (Government of India, 2016) was calculated using the Slovin's formula and was found to be 384 at $95 \%$ confidence level. Multilevel mixed sampling technique was used where initially the state of Tamil Nadu was divided into four geographical zones (North, South, Center and East) and the districts containing a relatively high number of colleges in each segment were identified through area sampling. Then a database was built compiling the details regarding all the colleges present in each of the selected districts. Using the database, the target colleges were picked at random (random sampling technique) and the questionnaires were sent directly to all the faculty members affiliated with these colleges (either in online or offline mode). Finally, the researcher was able to collect responses from a total of 410 participants. Of the 410 surveys collected, 11 were found to be invalid due to lack of completion and internal conflict within the responses. Hence, a total of 399 valid surveys were considered for the data analysis process.

\section{Research Instrument}

The questionnaire developed for the survey consisted of three primary sections - Demographic profile, questions regarding the availability of facilities required for supporting social media interventions and factors influencing the acceptance of technology-based educational aids among the faculty members - Attitude, technological facilities, Perceived ease of use and Intention to use - in Tamil Nadu. The statements that were intended to measure these factors were extracted from existing empirical studies (given under the reference section in Table 1) and were reframed to fit the context of the present investigation. The reliability of the factors was analyzed using Cronbach's alpha technique. The summarized output in the below table (Table 1) denotes the presence of strong internal consistency ( $\alpha$ value $>0.7$ ) among all the four factors making the data highly reliable (Nunnaly, 1978).

Table 1. The Reliability of the Factors Measured Using Cronbach's Alpha

\begin{tabular}{lccc}
\hline Factors & $\begin{array}{c}\text { No. of } \\
\text { Statements }\end{array}$ & Reference & Cronbach's Alpha ( $\alpha$ ) \\
\hline Attitude & 6 & Dermentzi et al (2016); & .892 \\
Technological Facilities & 5 & Mäntymäki et al (2014); & .894 \\
Perceived Ease of Use & 4 & Tao and Fan (2017); & .816 \\
Intention to Use & 4 & Rana et al (2015) & .750 \\
\hline
\end{tabular}




\section{Findings}

Prior to the analysis process, the data collected for the study was examined for its normality and linearity. In order to determine the normality of the data distribution, the two primary dependent variables - Attitude and Intention - was tested using Q-Q Plots (Ghasemi and Zahediasl, 2012). It is clear from the plots given below (Figure 1) that the data points of both the dependent variables are majorly aligned in a linear fashion along the diagonals of the Q-Q Plots representing the normal distribution devoid of any skewness. With the data being normally distributed, it can be subjected to any form of parametric testing such as t-tests, ANOVA, correlation and regression, to mention a few.
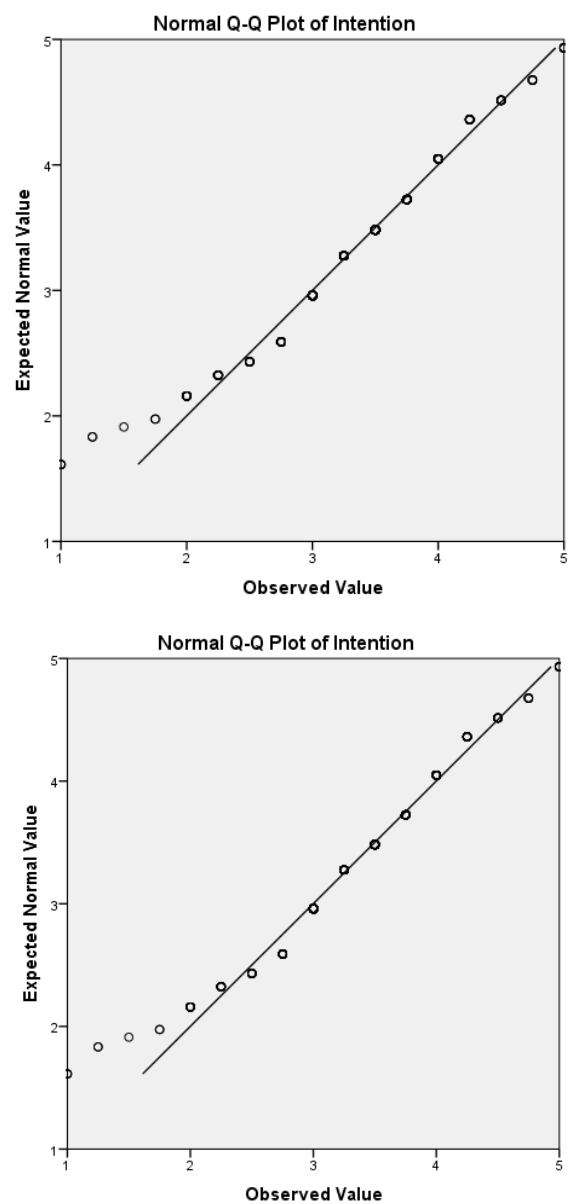

Figure. 1. Q-Q Plots of Attitude and Intention

\section{Demographics}

The samples for the present study were encompassed of faculty members from diverse academic positions. In terms of gender, faculty members of both the genders were represented more or less equally (Male $=53 \%$; Female $=47 \%$ ). Assistant professors were seen to occupy the major part (68\%) of the chart (Figure. 2) in relation to the respondents' academic designation. This predominance of assistant professors in the demographic profile of the samples is acceptable as it can be equated to the predominance of the assistant professors present 
( $n=155831$ ) in the overall research population - faculty members ( $n=196081)$ belonging to higher education institutions in Tamil Nadu (Government of India, 2016). The 'others' category of the academic designation contained varied titles such as Visiting Faculty, Teaching Fellow, Retired Professors, to name a few.

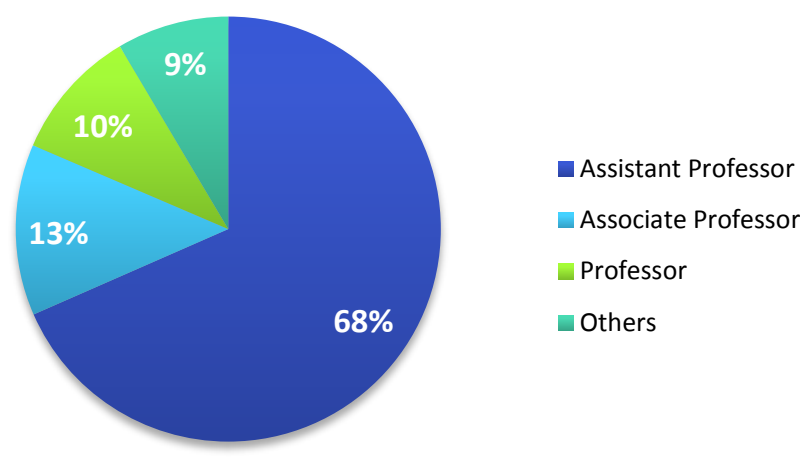

Figure.2. The Composition of Faculty Members Surveyed Based on Their Academic Designation

\section{Attitude towards the Use of Advanced Technological Aids for Educational Purposes}

One sample t-test was conducted to identify the perception (positive or negative) of the participants surveyed regarding the use of advanced technological aids such as social media tools in higher education classrooms. The faculty members were asked to respond to statements (intended to measure their attitude) on a five-point Likert scale having ' 1 ' as the least preferred and ' 5 ' as the highly preferred option. The neutral point -3- was fixed as the test value for the one sample t-test, so that a mean output above the test value will indicate a positive attitude and vice-versa.

Table 2. One Sample t-test for Analyzing the Attitude of Faculty Members

\begin{tabular}{|cc|ccc|} 
& Test Value & Significance & Mean Value $\overline{\boldsymbol{x}}$ & $\mathbf{t}$ value \\
\hline Attitude & 3 & .000 & 3.6500 & 17.146 \\
\hline
\end{tabular}

From the above table (Table 2) it can be inferred that the one sample test yielded a mean value of 3.65 with $t$-value of 17.15 at .0001 significance. The result along with a strong $t$ value suggests the prevalence of a positive attitude to some degree $(\overline{\mathrm{X}}>3)$ towards the integration and the use of social media tools in higher education classrooms among the faculty members in Tamil Nadu. Therefore, it can be stated that the possibility of faculty members welcoming social media tools into the educational domain is quite high.

Table 3. The Role of Environmental Settings (Urban/Rural) in Influencing the Attitude of the Faculty

\begin{tabular}{|l|l|l|c|c|c|}
\hline \multicolumn{2}{c}{} & Mean & \multicolumn{1}{c}{$\begin{array}{c}\text { Std. } \\
\text { Deviation }\end{array}$} & t & \multicolumn{1}{c|}{$\begin{array}{c}\text { Sig } \\
\text { (2-tailed) }\end{array}$} \\
\cline { 1 - 5 } $\begin{array}{l}\text { Environmental } \\
\text { Settings }\end{array}$ & Urban & 3.7037 & 0.71573 & \multirow{2}{*}{1.298} & 0.195 \\
\cline { 2 - 5 } & Rural & 3.5990 & 0.77308 & & \\
\hline
\end{tabular}


Also, the role played by the environmental setting of the institution in influencing the attitude of the faculty members towards social media interventions was analyzed using an independent sample t-test. The institutions were classified into two categories (urban and rural) based on the Indian government directory and analyzed. From Table 3, it can be inferred that there is no significant difference in the attitude of faculties belonging to rural and urban educational settings. Based on the mean value of attitude of the faculty members present in urban $\left(\bar{x}_{u r b a n}=\right.$ 3.70) and rural institutions ( $\overline{\mathrm{x}}_{\text {Rural }}=3.59$ ), it can be deduced that both have a fairly positive opinion regarding the use of social media tools as instructional and educational aids.

\section{Availability of Facilities in Educational Institutions}

In order to analyze the feasibility of social media integration within the college campuses present in Tamil Nadu, the respondents were enquired regarding the availability of basic facilities - electricity/power supply, computational resources and internet connectivityrequired for the seamless integration of any technological aid within the classrooms using a fivepoint Likert scale (' 1 ' signifying Low availability and ' 5 ' signifying high availability). The test value was once again set as 3 . Here the test value signified the availability of minimum facilities required for the advent of technological innovations as educational aids in these institutions.

Table 4. The Statistical Outputs of t-tests Analyzing the Availability of Basic Facilities Required for Social Media Interventions

\begin{tabular}{|lcccc|}
\hline Facilities & Test value & Significance & Mean Value & \multicolumn{1}{c|}{$\boldsymbol{t}$ value } \\
\hline Electricity/Power Supply & 3 & .000 & 2.49 & 6.820 \\
\hline $\begin{array}{l}\text { Computational Facilities } \\
\text { within the campus }\end{array}$ & 3 & .000 & 2.72 & 4.064 \\
\hline Smart Classroom Facilities & 3 & .004 & 2.80 & 2.933 \\
\hline Internet Availability & 3 & .001 & 2.76 & 3.328 \\
\hline
\end{tabular}

The results of all the t-tests done for analyzing the feasibility of higher education institutions availability of minimum facilities - in supporting the proper functioning of educational aids are compiled in Table 4. All the four basic facilities that are a mandatory requirement for social media or any technology-based educational intervention were found to be statistically not sufficient in colleges present in Tamil Nadu. According to the above result, it can be inferred that these institutions even lacked in having a continuous power supply $(\overline{\mathrm{x}}=2.49)$ which is the most basic requirement needed for social media applications to function in an effective manner.

In order to understand the role of environmental constraints - urban and rural settings of the educational institutions - in influencing the availability of infrastructural and technological facilities, a series of independent sample t-tests were conducted. The results are compiled in the table given below. From the below table (Table 5 ) it can be observed that there is no significant difference in terms of facilities available in institutions present in rural and urban areas.

With mean values of the essential resources (electricity: $X=2.49$, computational facilities: $X=$ 2.72 , smart classroom facilities: $X=2.80$ and internet connectivity: $X=2.76$ ) lying in the 'below neutral' area of the measurement scale and the environmental constrain playing a nonsignificant role, it can be deduced that urban and rural institution are equipped with a similar 
level of technological facilities that are insufficient for supporting technology based educational aids.

Table 5. The role of Environmental Settings (Urban/Rural) in Influencing the Availability of Facilities in Educational Institutions

\begin{tabular}{|lcc|}
\hline $\begin{array}{l}\text { Difference in Facilities available in } \\
\text { Urban and Rural Institutes }\end{array}$ & Significance & t value \\
\hline Electricity/Power Supply & 0.331 & 0.974 \\
\hline $\begin{array}{l}\text { Computational Facilities within the } \\
\text { campus }\end{array}$ & 0.190 & 1.314 \\
\hline Smart Classroom Facilities & 0.767 & 0.297 \\
\hline Internet Availability & 0.274 & 1.095 \\
\hline
\end{tabular}

\section{Regression Analysis}

With the sample data meeting all the essential statistical assumptions including normality, linearity and homoscedasticity, regression analysis was conducted for understanding the role of two crucial factors - availability of technological facilities and ease of use of educational aids - in influencing the attitude and intention of the faculty members regarding the use of technologically advanced educational aids. Though both the factors were found to significantly influence the attitude and intention of the faculty members, ease of use $(\beta=.711 ; t=20.118)$ was observed to create a huge impact on the faculty members' attitude regarding the use of technological interventions for education. Almost 50.4\% (Adjusted $\mathrm{R}^{2}$ ) of the variations in the attitude of the faculty members can be foreseen by measuring the perceived ease of use (Table 6).

Finally, the influence of attitude over the intention to use advanced technologies for education purposes was analyzed. Based on the regression output, it was evident that almost $21.8 \%$ (Adjusted $\mathrm{R}^{2}$ ) of intention in using such educational aids is formed based on the faculty members' attitude towards technology $(\beta=.470 ; t=10.596)$.

Table 6. Regression Output of Factors Being Analyzed

\begin{tabular}{|llll|} 
& $\mathbf{R}^{2}$ (Adjusted $\mathbf{R}^{2}$ ) & $\boldsymbol{\beta}$ value & t value \\
\hline $\begin{array}{l}\text { Technological Facilities - } \\
\text { Intention }\end{array}$ & $0.094(.092)$ & 0.307 & $6.428^{* * *}$ \\
\hline $\begin{array}{l}\text { Perceived Ease of Use - } \\
\text { Intention }\end{array}$ & $0.197(.195)$ & 0.711 & $0.118^{* * *}$ \\
\hline $\begin{array}{l}\text { Technological Facilities - } \\
\text { Attitude }\end{array}$ & $0.116(.114)$ & 0.341 & $7.219^{* * *}$ \\
\hline $\begin{array}{l}\text { Perceived Ease of Use - } \\
\text { Attitude }\end{array}$ & $0.505(.504)$ & 0.711 & $20.118^{* * *}$ \\
\hline Attitude - Intention & $0.220(.218)$ & 0.470 & $10.596^{* * *}$ \\
\hline
\end{tabular}




\section{Discussion and Conclusion}

The analysis of the current study revealed that the faculty members affiliated with the Indian higher education system hold an optimistic attitude towards the use of social media technologies as educational aids. Additionally, it was identified that attitude is a crucial factor that contours the faculty members' intention to employ these aids for instruction and other educational activities. In this connection, it can be inferred that both, the faculty members affiliated to technologically rich institutions that exists in developed countries (Coleman et al, 2018; Carpenter \& Krutka, 2014; Charleson \& Lyall, 2014; Jacquemin et al, 2014) and those associated with the institutes present in developing nations show equal level of enthusiasm towards the educational use of social media technologies and are likely to encourage this behavior among their students.

On analyzing the feasibility of the Indian higher education classrooms in supporting the successful functioning of social media or technology-based educational aids, it was found that irrespective of its environmental setting (rural/urban), the institutions lacked in providing the minimum facilities needed for accessing and using the social web for educational purposes. If this scenario prevailed, there are high chances that it might adversely affect the introduction and proper functioning of social media tools as education interventions. Hence, it is prudent to improve the overall technological infrastructure of the institutions present in developing and underdeveloped nations prior to the introduction of such interventions to avoid widening the imbalance and inequality in education of these countries (Yang \& MacLeod, 2018).

The present study provides an overview of the current scenario regarding the infrastructural and technological standards prevailing in the higher educational institutions of India. Irrespective of the environmental settings, it was found that all the institutions on an average lacked the basic facilities that are essential for supporting technological interventions. Though the faculty members were identified to have a positive attitude - highly influenced by the 'perceived ease of use' factor - towards welcoming technological aids into their classrooms, the absence of basic facilities may hinder the acceptance and successful implementation of these educational interventions. Social media is predicted to uplift the educational domain at a massive level and this can be achieved only by adopting parallel measures for upgrading the infrastructural and technological standards of the institutions. Also in a broader context, it is important to develop technology-based educational aids that can sustain these conditions and work efficiently with the resources available in higher education classrooms present in developing nations.

\section{References}

Barczyk, C. C. \& Duncan, D. G. (2013). Facebook in higher education courses: An analysis of students' attitudes, community of practice, and classroom community. International Business and Management, 6(1), 1-11.

Barry, D. S., Marzouk, F., Chulak-Oglu, K., Bennett, D., Tierney, P., \& O'Keeffe, G. W. (2016). Anatomy education for the YouTube generation. Anatomical Sciences Education, 9(1), 90-96.

Brown, S. A. (2012). Seeing Web 2.0 in context: A study of academic perceptions. The Internet and Higher Education, 15(1), 50-57. 
Carpenter, J. P. \& Krutka, D. G. (2014). How and why educators use Twitter: A survey of the field. Journal of Research on Technology in Education, 46(4), 414-434.

Charleson, D. \& Lyall, M. (2014). The new communication: Using new and social media as a basis for instruction and assessment in higher education. Screen Education, 75, 72-76.

Coleman, B. C., Pettit, S. K., \& Buning, M. M. (2018). Social Media Use in Higher Education: Do Members of the Academy Recognize Any Advantages? The Journal of Social Media in Society, 7(1), 420-442.

Clement, A. \& Murugavel, T. (2015). English for Employability: A Case Study of the English Language Training Need Analysis for Engineering Students in India. English Language Teaching, 8(2), 116-125.

Dermentzi, E., Papagiannidis, S., Toro, C. O., \& Yannopoulou, N. (2016). Academic engagement: Differences between intention to adopt Social Networking Sites and other online technologies. Computers in Human Behavior, 61, 321-332.

De Wever, B., Hämäläinen, R., Voet, M., \& Gielen, M. (2015). A wiki task for first-year university students: The effect of scripting students' collaboration. The Internet and Higher Education, 25, 37-44.

Ganem-Gutierrez, G. A. (2014). A sociocultural theory approach to the design and evaluation of 3D virtual world tasks. In M. Gonz alez-Lloret, \& L. Ortega (Eds.), Technology and tasks: Exploring technology-mediated TBLT (pp. 213-238). Washington, DC: Georgetown University Press.

Gao, F., Luo, T., \& Zhang, K. (2012). Tweeting for learning: A critical analysis of research on microblogging in education published in 2008-2011. British Journal of Educational Technology, 43(5), 783-801.

Ghasemi, A. \& Zahediasl, S. (2012). Normality tests for statistical analysis: a guide for nonstatisticians. International journal of Endocrinology and Metabolism, 10(2), 486.

Government of India (2016). All India survey on higher education (2015-16). Ministry of Human Resource Development, Department of Higher Education, New Delhi, India.

Gros, B. \& López, M. (2016). Students as co-creators of technology-rich learning activities in higher education. International Journal of Educational Technology in Higher Education, 13(1), 28.

Gupta, A. K. (2016). Scope and implications of social media in the context of higher education: review of researches. MIER Journal of Educational Studies, Trends and Practices, 4(2), 231-253.

Hew, K. F. \& Cheung, W. S. (2013). Use of Web 2.0 technologies in K-12 and higher education: The search for evidence-based practice. Educational Research Review, 9, 47-64.

Hrastinski, S. \& Aghaee, N. M. (2012). How are campus students using social media to support their studies? An explorative interview study. Education and Information Technologies, 17(4), 451-464.

Jacquemin, S. J., Smelser, L. K., \& Bernot, M. J. (2014). Twitter in the higher education classroom: A student and faculty assessment of use and perception. Journal of College Science Teaching, 43(6), 22-27. 
Jain, A., Bansal, R., Singh, K. D., \& Kumar, A. (2014). Attitude of medical and dental first year students towards teaching methods in a medical college of northern India. Journal of Clinical and Diagnostic Research, 8(12), XC05-XC08

Kaplan, A. M. \& Haenlein, M. (2010). Users of the world, unite! The challenges and opportunities of Social Media. Business Horizons, 53(1), 59-68.

Karvounidis, T., Chimos, K., Bersimis, S., \& Douligeris, C. (2014). Evaluating Web 2.0 technologies in higher education using students' perceptions and performance. Journal of Computer Assisted Learning, 30(6), 577-596.

Kassens-Noor, E. (2012). Twitter as a teaching practice to enhance active and informal learning in higher education: The case of sustainable tweets. Active Learning in Higher Education, 13(1), 9-21.

Kitsantas, A., Dabbagh, N., Chirinos, D. S., \& Fake, H. (2016). College students' perceptions of positive and negative effects of social networking. In T. Issa, P. Isaias, and P. Kommers (Eds.), Social networking and education: Global perspectives (pp. 225-238). Heidelberg: Springer.

Lan, L., Gou, X., \& Xi, J. (2011). SNS communication model applying in network education system. In Y. Yu, Z. Yu, and J. Zhao (Eds.), Computer science for environmental engineering and ecoinformatics (pp. 195-200). Heidelberg: Springer.

Lee, L. (2017). Learners' perceptions of the effectiveness of blogging for L2 writing in fully online language courses. International Journal of Computer-Assisted Language Learning and Teaching, 7(1), 19-33.

Manca, S. \& Ranieri, M. (2013). Is it a tool suitable for learning? A critical review of the literature on Facebook as a technology-enhanced learning environment. Journal of Computer Assisted Learning, 29(6), 487-504.

Mäntymäki, M., Merikivi, J., Verhagen, T., Feldberg, F., \& Rajala, R. (2014). Does a contextualized theory of planned behavior explain why teenagers stay in virtual worlds? International Journal of Information Management, 34(5), 567-576.

Means, B. (2010). Technology and education change: Focus on student learning. Journal of Research on Technology in Education, 42(3), 285-307.

Miyazoe, T. \& Anderson, T. (2010). Learning outcomes and students' perceptions of online writing: Simultaneous implementation of a forum, blog, and wiki in an EFL blended learning setting. System, 38(2), 185-199.

Muniyandy, S., Khuenyen, N., Yap, C. G., Shogo, M., My, N. A., Chowdhury, M. E. H., \& Musa, A. F. (2015). Influence of YouTube videos on the learning of tablet-and capsule-formulation by Malaysian pharmacy students: A pilot study. Pharmacy Education, 15, 248-251.

Nunnally, J. C. (1978). Psychometric theory (2nd ed.). New York: McGraw-Hill.

Orús, C., Barlés, M. J., Belanche, D., Casaló, L., Fraj, E., \& Gurrea, R. (2016). The effects of learner-generated videos for YouTube on learning outcomes and satisfaction. Computers \& Education, 95, 254-269.

Parise, S. (2015). Using voice thread to socialize online presentations. In V. L. Crittenden, K. Esper, N. Karst, and R. Slegers (Eds.), Evolving entrepreneurial education: Innovation in the Babson classroom (pp. 349-363). Bingley, UK: Emerald.. 
Pavo, M. Á. H. \& Rodrigo, J. C. (2015). Interaction analysis of a blog/journal of teaching practice. The Internet and Higher Education, 27, 32-43.

Rana, N. P., Dwivedi, Y. K., Lal, B., \& Williams, M. D. (2015, July). Assessing citizens' adoption of a transactional e-government system: Validation of the extended decomposed theory of planned behavior (DTPB). PACIS Proceedings. Retrieved on 05 April 2018 from https://aisel.aisnet.org/cgi/viewcontent.cgi?article=1039\&context=pacis2015

Ryan, A. \& Tilbury, D. (2013). Flexible Pedagogies: new pedagogical ideas. London: Higher Education Academy.

Sánchez, R. A., Cortijo, V., \& Javed, U. (2014). Students' perceptions of Facebook for academic purposes. Computers \& Education, 70, 138-149.

Sun, Y. C. (2009). Voice blog: An exploratory study of language learning. Language Learning \& Technology, 13(2), 88-103.

Tackett, S., Slinn, K., Marshall, T., Gaglani, S., Waldman, V., \& Desai, R. (2018). Medical education videos for the world: An analysis of viewing patterns for a Youtube channel. Academic Medicine: Journal of the Association of American Medical Colleges. DOI: $10.1097 / \mathrm{ACM} .0000000000002118$

Tang, E. \& Lam, C. (2014). Building an effective online learning community (OLC) in blog-based teaching portfolios. The Internet and Higher Education, 20, 79-85.

Tess, P. A. (2013). The role of social media in higher education classes (real and virtual) - A literature review. Computers in Human Behavior, 29(5), A60-A68.

Tao, C. C. \& Fan, C. C. (2017). A modified decomposed theory of planned behaviour model to analyze user intention towards distance-based electronic toll collection services. Promet - Traffic \& Transportation, 29(1), 85-97.

Van Noorden, R. (2014). Online collaboration: Scientists and the social network. Nature news, 512(7513), 126.

Veletsianos, G. \& Navarrete, C. (2012). Online social networks as formal learning environments: Learner experiences and activities. The International Review of Research in Open and Distributed Learning, 13(1), 144-166.

Wang, W. H., Hao, Y. M., Cao, Y. H., \& Li, L. (2014). A cloud-based real-time mobile collaboration wiki system. Applied Mechanics and Materials, 441, 928-931.

Ward, T., Falconer, L., Frutos-Perez, M., Williams, B., Johns, J., \& Harold, S. (2015). Using virtual online simulations in Second Life ${ }^{\circledR}$ to engage undergraduate psychology students with employability issues. British Journal of Educational Technology, 47(5), 918-931.

West, D. M. (2015). Digital divide: Improving Internet access in the developing world through affordable services and diverse content. New York: Center for Technology Innovation at Brookings. Retrieved on 5 April 2018 from https://www.brookings.edu/wp-content/ uploads/2016/06/West_Internet-Access.pdf

Yang, H. H., Zhu, S., \& MacLeod, J. (2018). Promoting education equity in rural and underdeveloped areas: Cases on computer-supported collaborative teaching in China. EURASIA Journal of Mathematics, Science and Technology Education, 14(6), 23932405. 
CONTEMPORARY EDUCATIONAL TECHNOLOGY, 2018, 9(3), 284-296

https://doi.org/10.30935/cet.444114

Zheng, B., Yim, S., \& Warschauer, M. (2018). Social media in the writing classroom and beyond. In J. I. Liontas (Ed.), The TESOL Encyclopedia of English Language Teaching, (pp. 1-5). DOI: 10.1002/9781118784235.eelt0555

Correspondence: Mangala Vadivu Vivakaran, Doctoral Research Scholar, Department of Media Sciences, Anna University, Chennai, India 